Article

\title{
Access to and Benefit Sharing of Plant Genetic Resources: Novel Field Experiences to Inform Policy
}

\author{
Ronnie Vernooy ${ }^{1, *}$ and Manuel Ruiz ${ }^{2}$ \\ 1 Bioversity International, Via dei Tre Denari 472/a, Maccarese 00057, Italy \\ 2 Peruvian Society for Environmental Law (SPDA), Prolongación Arenales 437, Lima 27, Peru; \\ E-Mail: mruiz@spda.org.pe \\ * Author to whom correspondence should be addressed; E-Mail: r.vernooy@cgiar.org; \\ Tel.: +39-06-611-8280; Fax: +39-06-6197-9661.
}

Received: 22 April 2013; in revised form: 1 June 2013 / Accepted: 6 June 2013/

Published: 13 June 2013

\begin{abstract}
A number of national and international policy processes are underway to allow for the development of sui generis systems to protect local natural and genetic resources and related knowledge about their management, use and maintenance. Despite agreements reached on paper at international and national levels, such as the Nagoya Protocol on access to genetic resources and the fair and equitable sharing of benefits derived from their use, and the International Treaty on Plant Genetic Resources for Food and Agriculture, progress in implementation has been slow and in many countries, painful. Promising examples from the field could stimulate policy debates and inspire implementation processes. Case studies from China, Cuba, Honduras, Jordan, Nepal, Peru and Syria offer examples of novel access and benefit sharing practices of local and indigenous farming communities. The examples are linked to new partnership configurations of multiple stakeholders interested in supporting these communities. The effective and fair implementation of mechanisms supported by appropriate policies and laws will ultimately be the most important assessment factor of the success of any formal access and benefit sharing regime.
\end{abstract}

Keywords: access; benefit sharing; Convention on Biological Diversity; International Treaty on Plant Genetic Resources for Food and Agriculture; participatory plant breeding; plant genetic resources 


\section{Introduction: The Challenge of Moving from Concept to Practice}

Local practices in biodiversity conservation, crop improvement and natural resource management are under stress around the world. The disintegration or disappearance of these practices goes hand in hand with the loss of traditional and indigenous knowledge related to the management of crops, trees, animals, land and water [1]. A number of national and international policy processes are underway to allow for the development of sui generis systems to protect local natural and genetic resources and related knowledge about their management, use and maintenance [2]. The best known are the longstanding negotiations of the International Regime on Access to Genetic Resources and Benefit Sharing under the Convention on Biological Diversity (CBD) and those of the International Regime for the Protection of Traditional Knowledge under the World Intellectual Property Organization (WIPO). A third, the International Treaty on Plant Genetic Resources for Food and Agriculture (ITPGRFA), while recognizing national sovereign rights over plant genetic resources, represents a multilateral system for facilitated access to a limited number of agricultural crops for the fair and equitable sharing of the benefits arising from their use [3]. So far, despite agreements reached on paper, progress in implementation of these agreements has been slow and painful [4].

In the last decade, access and benefit-sharing issues have increasingly become part of the international and national policy and legal agendas related to biodiversity in general and genetic resources in particular. As such, fair and equitable access and benefit sharing has acquired what could be called a formalized nature. For example, at the national level, the Andean Community was the first regional bloc to adopt a comprehensive policy and legal framework regarding access to genetic resources and the protection of traditional knowledge, as a pioneering step in implementing the equity and fairness principles of the CBD. The 1996 Decision 391 of the Andean Community on a Common Regime on Access to Genetic Resources regulates who may have access to the region's genetic resources and under what conditions. It also sets general obligations for the recognition and protection of traditional knowledge. The whole Andean process to develop ABS and traditional knowledge frameworks arose from prior discussions regarding a regime to protect plant breeders' rights and concerns over access to and use of native and wild genetic materials.

Increasingly, customary practices at local level are under pressure to conform to this formalization processes without prior consultation, participation or negotiation. We have called this process originating in the international and national arenas, "the race to the bottom" [5]. However, at the local level, many of the issues continue to be dealt with through customary (sometimes formalized, often informal) practices, rules and regulations. Benefit sharing has been taking place regardless of formal policy and legal mandates; and sometimes in opposition to ineffective or unfair policies and laws (for a discussion of the complex situation in Brazil, see Santilli [6]).

In this article, we present a number of novel access and benefit sharing (ABS) practices that are built on local realities while taking into consideration the formalization process. Case studies are from China, Cuba, Honduras, Jordan, Nepal, Peru and Syria (detailed cases can be found in Ruiz and Vernooy [7]). The examples aim to inspire implementation of ABS agreements and serve as inputs for the further refinement of related policy and legal instruments. The examples are grounded in the practices of local and indigenous farming communities and linked to new partnership configurations of multiple stakeholders interested in supporting these communities. This article thus serves as input to a grounded 
approach to policy development [8] The effective and fair implementation of mechanisms, supported by appropriate policies and laws, will ultimately be the most important assessment factor of success of any access and benefit sharing regime [9-11].

\section{Conceptual Reflections}

The CBD triggered intense intellectual debate about the concepts of access and benefit sharing as well as about the legal protection of traditional knowledge, considered a prerequisite for fair and equitable benefit sharing. However, the debate is not only about the meaning of concepts. It also draws attention to the processes leading to their definition, i.e., participation in decision-making at various levels [12-19]. The debate has led to a growing number of frameworks designed to protect traditional knowledge, based on new thinking about how to preserve ancestral traditional knowledge and ensure compensation when it is used. One of the major challenges has been to find appropriate connection and synergies between customary practices and formal state law. Frameworks that are treating traditional knowledge as a "commodity" owned by individuals obviate the fact that traditional knowledge is an element in a cultural context where direct or potential use is but one of the many ways in which indigenous peoples and communities (including farmers) access and give meaning to genetic resources. For many local communities around the world, genetic resources also have religious, ethical, spiritual and sociocultural meaning and value. Formal appropriation or assignation of genetic resources is alien to these values. At the same time, communities are advocating further respect and recognition of local practices, where, for example, biocultural protocols are designed, a priori, to set the standard under which traditional knowledge and resources may be accessed or used. Our view is that new policy and legal development should focus on collective benefit-sharing mechanisms in recognition of both the nature of plant genetic resources, and the customary practices of their management, in particular, but not solely those for food and agriculture.

Perspectives on participation in decision-making processes concerning access, benefit sharing and protection of traditional knowledge range from a narrow and technical interpretation, to a broad and inclusive approach. The former tends to regard participation as an end in itself (e.g., participation is enacted by inviting farmers to meetings) while the latter considers participation as a means to an end (e.g., participation implies that farmers' interests are reflected in decisions taken in meetings and that some kind of result is generated that serves farmers' needs). We argue in favor of the latter view. This is based on two considerations. First, rural livelihoods in most regions of the world are influenced by a wide range of policies (e.g., land, water, credit, education, health). Second, it is through actual benefits that rights are fully realized. The latter kind of participation is illustrated by the intellectual input of communities into bioprospecting and plant breeding processes, in particular, but not only during the early stages of research and development, that has resulted in the production of new goods and services in a wide range of industries, including pharmaceuticals, biotechnology and agro-industry, and the flow of some form of benefit back to communities [18]. Participatory plant breeding (PPB), central to the case studies discussed here, has given farmer communities not only a say in decision-making and defining their production priorities and needs, but also has led to the development of new varieties that respond to farmers' needs. This kind of meaningful involvement in the research process in itself can be seen as a form of benefit sharing [20,21]. 


\section{Methodology: Framework and Case Studies}

Case studies are a useful method to deepen a field of knowledge and experience. The case studies are organized around a common analytical framework that includes recognition, access, benefit sharing, and policy and legal environment including space for participation by stakeholders. The five key research questions derived from this framework are: How do people at the local level perceive and assess ABS questions, especially in light of national and international guidelines, model laws and other new forms of defining and regulating ABS regarding biodiversity resources? How can local and indigenous knowledge and practices be acknowledged, recognized and valued? How can the principles of prior informed consent and mutually agreed terms be respected? How can the roles and responsibilities and the forms of participation of right-holders and stakeholders be defined? How can feasible ABS mechanisms, both formal and informal, be designed, implemented and monitored? Answers to these research questions across the case studies will be presented in Section 4.

All cases represent long-term, field-based action-oriented research initiatives involving multiple stakeholders that address key issues and access and benefit sharing questions in practice. All are characterized by their direct engagement with policy- and law-making processes at the national level, bringing field experiences, insights and lessons to the attention of key decision-makers. Five case study team members participate directly in national committees or platforms on behalf of their organization or constituency (in China, Cuba, Jordan, Nepal and Peru). Some team members have been and continue to be active in regional or international fora dealing with access and benefit policies and legislation (in Peru and Nepal). In all cases except Peru, teams have been at the forefront in introducing, testing and adapting participatory plant breeding, most for more than a decade now. The Peru case represents an example of a champion in the field of biopiracy study and prevention, awareness raising and policy influence, complementing the other cases by using a different but important lens. The case study teams all have a common goal: improving farmers' and indigenous peoples' livelihoods by ensuring food security, better food quality, improved well-being, support for local cultural and collective identities, the dynamic use and maintenance of biodiversity and collective capacity for innovation.

\subsection{A Summary of the Cases}

Since the CBD came into force, Peru has been very active in developing frameworks for ABS and protecting traditional knowledge, because of its strong concern over the misuse, illegal use and misappropriation (biopiracy) of national genetic resources and indigenous peoples' traditional knowledge. The Peruvian case study offers an overview of the implementation of and some of the overarching lessons learned from researching the implementation of access and benefit sharing policies and laws in Peru based on an in-depth review of biopiracy practices. This phenomenon is now well understood in the country including at local level [22]. What is important and also well acknowledged is that traditional exchanges of genetic resources (i.e., seeds) among farmers and the use of improved local varieties are not seen as biopiracy. These practices have been specifically excluded in national legislation. The case study was led by SPDA and carried out in cooperation with various government and non-government agencies. 
Syria was a pioneer in the Middle East in participatory plant breeding (PPB) with a focus on barley improvement. This approach enables farmers to benefit from their contributions to the global genetic pool, for example, by adding value to their crops, improving their livelihoods and increasing their income. The PPB work in Syria, led by the International Center of Agricultural Research in Dry Areas (ICARDA) in cooperation with farmers from different regions of the country, served later as a learning ground for similar efforts in other countries in the region, e.g., Algeria, Morocco, Egypt, Jordan (see next paragraph) and Yemen. PPB is one of the most common types of benefit sharing related to farmers' rights referred to in the ITPGRFA. Several publications are available about the PPB work in Syria $[23,24]$.

Jordan, in contrast with Syria, represents a very recent example of dealing with ABS issues. Jordan's government has developed a supportive institutional environment for the country's agricultural sector. This case study, led by the National Center for Agricultural Research and Extension (NCARE) and carried out in cooperation with other government agencies and farmers, describes the relevant agricultural policies, laws and international agreements and how they were enacted, through the lens of the country's efforts to introduce and institutionalize PPB. PPB has been very well received and expanded from barley to other crops in a relatively short time.

In April 2006, Honduras entered into a free-trade agreement with the United States: the Dominican Republic-Central American Free Trade Agreement (DR-CAFTA). This agreement will have a profound effect on smallholder agriculture, on which a large percentage of the population in the poorest countries of the region depends. This case study examines the impact of the agreement on ABS of plant genetic resources for smallholder Honduran farmers and their seed systems, through the lens of participatory plant breeding and farmers' rights. The experience with farmer research groups in two municipalities provided examples of various degrees of farmer and breeder involvement in PPB. For each of the main types, the Honduras team researched the ABS implications. The types include: (i) Farmer-led-Through intensive selection, farmers improve a local landrace and release it with a new name. This process is supported by a local NGO. (ii) Farmer-breeder collaboration-At the request of farmers (and in conjunction with donor support for PPB), the breeder crosses a local landrace with improved materials and returns segregating populations to farmers for intensive selection. Farmers select certain lines and release varieties with new names. The NGO acts as an intermediary between the breeder and farmers, providing detailed feedback on the trials to the breeder and technical assistance to farmers. (iii) Breeder-led-The breeder provides farmers with improved lines, e.g., through regional trials, and farmers select certain materials that are not selected elsewhere in the country or region. These become local varieties and are given local names. The NGO provides technical support to the farmers and information for use in analyzing data from regional trials to the breeder. The case study was coordinated by the non-government organization FIPAH with support of the University of Guelph of Canada and in cooperation with various farmer groups [25]. The study concludes that farmers' rights are unlikely to be defensible, notwithstanding the ITPGRFA.

In Southwest China, farmers' seed systems continue to play a major role in the seed supply system and maintaining the diversity that is essential to sustain the livelihoods of all farmers and the country at large. This case study presents the experience of a decade of efforts, led by a number of formal system research agencies in cooperation with government agencies, non-government organizations, local extension agents and farmers, to link community-based action research on the conservation of 
agricultural biodiversity and crop improvement (maize in particular) with relevant policy- and law-making processes at the national level by engaging key decision-makers in the rural development policy arena at local, provincial and national levels. The team identified six stages in the PPB selection and breeding process that serve as entry points for ABS discussions and experimentation: germplasm registration, germplasm collection and conservation, germplasm use in hybrid breeding, germplasm use for OPV improvement, variety release and seed multiplication. Although results have been positive as documented in a detailed study of ten years of efforts to create synergies between the formal and informal seed systems led by Song and Vernooy [11], there is still insufficient attention to farmers' contributions to the maintenance and improvement of genetic resources and their rights in general.

Cuban agriculture is struggling to survive under difficult conditions, as is much of the country's economy. Farmers across the island, together with a number of young agricultural researchers, are rediscovering that necessity is the mother of invention. They are reviving the seed systems through an approach known as participatory seed diffusion (PSD). PSD is a way to integrate diversity seed fairs with farmer experimentation. Seed diversity fairs are events where plant breeders, farmers and extension agents have free access to diverse varieties of one or more crops. Varieties from formal and informal seed systems are sown under the usual cultural conditions in the target environment, then farmers are given free access to all the seeds and can choose the varieties they want in the fields. They take seeds from the selected varieties (or materials under development) back home for further experimentation. Once farmers have seen the favorable results of these experiments, they have tended to organize themselves into research groups. Each diversity node or nucleus promotes knowledge, social organization and entrepreneurial activities characterized by intense genetic flows, value-added efforts and continuing discussion around local innovation more broadly. In the process, new forms of participation and cooperation have emerged and, through these, new ABS arrangements are evolving. This case study, led by a formal system research agency in cooperation with government agencies and farmer groups, provides an overview of the revitalization process that grew from a very localized initiative to diversify seed supplies to a national program to innovate rural development [26].

It was only after Nepal became a party to the CBD in February 1993 that the government and several NGOs began to discuss the importance of integrating ABS issues into national policies. This case study describes innovative research and development efforts based on the concept of community-based biodiversity management to give concrete meaning to the concept of ABS in practice and to create a policy and legal environment promoting the diversity, both biological and sociocultural, on which Nepal depends [27,28]. CBM aims to demonstrate and validate basic ways to implement ABS and ensure farmers' rights. The mechanisms include practices useful for documentation, adding value, sustainable use and conservation, providing access and sharing the accrued benefits fairly and equitably. Another key area of activity is experimentation and research on novel institutional structures at the community and national levels that can carry out functions to ensure farmers' rights, including implementing a sui generis ABS regime. The case study was coordinated by two non-government organizations in cooperation with government agencies and farmer communities. 


\section{Field Experiences}

The cases have a number of similarities, which begin with recognition of the custodians of biodiversity. Proper recognition is a precondition for any meaningful access and benefit sharing mechanism or regime. In policy and legal spheres, using this principle as a basis remains work in progress. Some countries, such as Honduras, continue to disregard it, while others, such as Peru, Nepal and China, are adopting a more positive attitude and an enabling environment. Similarities can be found in the principles that inform the efforts, e.g., farmers and indigenous people are knowledgeable and have much to contribute to the conservation and improvement of genetic resources, but can also greatly benefit from interaction and cooperation with others. Differences concern the scope of the efforts, e.g., from a focus on biopiracy (Peru) or PPB (Syria) to a broader perspective on local agricultural development (Cuba, Nepal) and the policy and legal context in which the actions are taking place. In some cases, there are constraints or even hostility (Honduras); in others, more openness (Jordan) and encouragement (China, Nepal). In some countries, there is little or no space for policy dialogue (Honduras, Syria). In China, collaborative policy experimentation takes place.

\subsection{Local Perceptions and National Definitions}

In the seven case study countries, ABS issues have only quite recently reached local communities, sometimes through negative experiences, such as biopiracy, and sometimes through positive ones, such as PPB. To a considerable extent, farmers' local-level agricultural practices (e.g., seed exchange, joint experimentation, community fund) have traditionally been based on some form of equitable benefit sharing that stems from everyday and ancestral practices in some cases, rather than from specific legal mandates. In most cases, ABS law is detached from local realities, while ABS legal development is characterized by asymmetries in access to information, (contract) negotiation skills and language barriers. Farmers in all seven case study countries continue to rely heavily on informal seed systems, for example, in which a variety of modes of non-monetary and monetary exchange exist and through which recognition (e.g., farmers as expert seed producers), access (e.g., through biodiversity fairs) and benefit sharing (e.g., newly developed varieties given away as gifts to neighbors to be tested) take shape. It is only since the establishment of the CBD that a legal obligation has arisen in this regard. Concerns about ABS have often appeared at the crossroads of two forces: emerging from local practical experience and insights on one hand (e.g., after 5-10 years of PPB efforts when new varieties had been developed and teams were wondering what to do with them), and awakened by developments in national and international arenas on the other (countries actively seeking to develop ABS policies, e.g., Peru, and, more recently, Nepal and China). As exemplified by the case of Jordan, the evolution of PPB led almost naturally to the realization by the research team that breeding programs are not just a matter of technical expertise, but also that important policy and legal aspects have an impact on PPB. In the current policy context, these aspects are being phrased in terms of ABS questions, including such fundamental questions as who owns or has property rights over seeds and breeding materials. The success of the barley program and its scaling out to other crops created a need to address these questions, reinforced by growing international awareness and pressure to deal with them. 
A similar process occurred in other cases, e.g., Nepal and China in particular. It was only after Nepal became a party to the CBD, that the government and some NGOs started to discuss the importance of mainstreaming ABS issues in national policies. Similarly, following the country's engagement in the FAO's Commission on Plant Genetic Resources, national-level discussions were held to undertake initiatives for the conservation, management and use of plant genetic resources and, in this process, seek options to address farmers' concerns. Nepalese NGOs made use of this policy space to bring local perspectives and interests to the table. Inversely, international concerns and issues were also introduced into local-level discussions and reflections.

In the seven cases, farmers and indigenous communities have their own ideas, interests and practices concerning recognition and $\mathrm{ABS}$, but they are often not expressed in formal ABS language. They are also usually maintained, transferred and adapted tacitly, that is, not written down, although some changes are occurring, in part due to the sort of development initiatives described in the case studies. Traditions and customary law are, in this regard, a guiding force in these contexts. They are often based on collective identities and forms of reciprocity, although in recent years these have come under strong pressure from privatization and commercialization forces, as the China case in particular illustrates. However, there are few societal incentives for farmers to maintain the local seed system other than for their own good while, until recently, almost everywhere, breeders could obtain germplasm from farmers' fields for free. Farmers have no or little control over their genetic resources. Given that there is no societal compensation for farmers' conservation efforts, farmers' awareness about the wider importance of genetic diversity conservation has remained relatively weak. This is beginning to change now, though, as the cases demonstrate.

\subsection{Recognition and Valuation}

The seven case study teams carried out the research based on respect for and recognition of the knowledge and practices of local communities. They considered prior informed consent (PIC) to be a means to redress the asymmetrical relationship between those seeking access (usually research institutions) and the holders or custodians of knowledge and resources. PIC or more recently free prior informed consent refers to consent by communities and farmers to the use of their knowledge and resources, based on a well informed and timely process in which decisions are based on appropriate data and information provided by potential users of the traditional knowledge and resources. One of the main practical difficulties (which was to some extent perceived by Jordan breeders and farmers) is identification of who precisely is entitled to grant PIC and agree to terms: a farmer and if so, which farmer, a group of farmers or communities and if so, which farmers? The case study teams also faced this difficulty when deliberating benefit sharing options. MATs on the other hand, refer to a negotiation phase during which communities and farmers discuss and agree how their seeds and materials may be accessed and used, by whom, under what conditions and for what specific purposes. MATs or similar agreements (such as pioneered by the Chinese team) are a means of responding to the participatory principle that governs PPB.

PIC remains very much a novel idea and practice. None of the cases had a formal form of PIC at the beginning of the initiative, although they all implicitly accepted the principle, and some (Nepal and, more recently, China) formalized PIC later. In Nepal, communities were trained to document the 
genetic resources and associated traditional knowledge in a community biodiversity register (CBR). If the CBRs are recognized in policy and legal frameworks as certification by the custodians of this information and a national CBR is compiled, it will facilitate the process of bioprospecting, provide the basis for ownership of genetic resources and associated traditional knowledge and specify the community to be involved in providing PIC. The recently signed novel ABS agreements in China are based on both PIC and MATs. They represent an inspiring example for other countries. In China, the team proposes that, within the existing legislation, farmers' rights can be protected through prior agreement and formal contracting between "parties" concerning the benefits to be shared. The contributions of farmers can be determined in various ways. The China case suggests that the contracting process could best be facilitated by an impartial third party. In addition to their role in providing germplasm, farmers' efforts in the PPB process should also be reflected in the contract. Third parties may also be effective in dispute settlement. Right now, as most of the cases indicate, farmers have little or no recourse if a dispute arises. This issue merits further attention and research, and evidence of how existing frameworks can be adapted and suited to address ABS obligations.

Within this context, local knowledge and practices are diverse and constantly changing. Farmers continue to conserve and manage landraces in their local seed systems, which are under increasing pressure from market forces. In China, for example, both government agencies and private-sector businesses are staging campaigns to sell hybrid seeds. For many researchers, the process of working with and learning from farmers has been one of awakening. In Cuba, although professional plant breeders faced a difficult economic situation after the country had to manage without the financial and technical aid from the Soviet Union, they continued their old, top-down approach believing that the best solution for all the problems in agriculture and plant breeding was "simple" technology substitution. A number of pioneers brought about change inspired by PPB experiences from elsewhere, based on the recognition that farmers are capable of experimentation and innovation and that, through joint efforts, perhaps better solutions could be found [20]. PPB starts with recognition of farmers' knowledge and expertise and includes the interest to build on it and strengthen it.

In Syria, scientists realized that users' participation in technology development may, in fact, increase its probability of success. In Jordan, PPB resulted in a dramatic change in attitude and behavior among breeders. They came to acknowledge and appreciate the knowledge and skills of farmers and began to look for ways to build on their expertise. They also became aware that benefits are not just the final products of the breeding process (i.e., improved and released varieties), but that sharing of knowledge and experience is also a form of benefit sharing, leading to new insights, new experiences, new diversity and the step-wise improvement of farmers' crops and seeds. This was a major discovery and an important opening up of the conventional approach and system.

Maize research in China is well organized and has produced good results, but it has been carried out mainly in favorable production regions. Less favorable regions have not been served well. This has been partly because those involved in traditional plant-breeding science assume that farmers are less knowledgeable than breeders, that selection must be done under optimum conditions, that cultivars must be genetically uniform and widely adaptable over large geographic areas and that landraces and open-pollinated varieties must be replaced by high-yielding varieties to ensure national food security. Issues such as biodiversity, farmers' diverse livelihoods and their contributions to crop improvement have been largely ignored. 
In Honduras, farmers' seeds are unprotected under DR-CAFTA, as is their indigenous knowledge. Explicit clearance for the use of traditional knowledge or seed varieties by a patent applicant does not have to be provided; nor is the location of origin or an arrangement for benefit sharing between the applicant and the knowledge or seed holders required. In China, there are formal public registration systems for germplasm at both provincial and national levels; however, the current "passport" information for germplasm mainly focuses on genetic and geographic information and lacks socioeconomic and cultural information about farmers and local communities. The custodians of genetic resources are treated as if they do not exist or do not matter in the formal system. To address this issue, the China team proposes improving the current registration system to place more emphasis on farmers' and communities' rights, recognizing their crucial roles in maintaining agricultural biodiversity in the field through both individual and collective efforts.

\subsection{Roles and Responsibilities}

Existing ABS policy and legal frameworks seek to organize how and under what conditions various actors involved in, for example, plant breeding, participate and engage in the breeding process or become involved in bioprospecting activities. This ranges from how breeding materials are obtained from in situ or ex situ sources to how benefits should be shared throughout the breeding cycle. One common element in almost all policy and legal frameworks, including those in Peru, Nepal and, more broadly, China, is that some form of government permit is required to access and use materials. With regard to ex situ materials stored in national (Honduras, Jordan, Syria) and/or provincial genebanks (China), several of the case study teams initially had great difficulties obtaining access to accessions for use by farmers, either directly or indirectly through cooperation with formal sector plant breeders.

Participatory approaches focus on meaningful, fair and iterative interaction. From PPB experiences around the world, we know this requires much effort [21]. Enhancement of the capacity of government as well as community institutions to develop the necessary skills remains a major task in all the study cases. In practical terms, it includes legal access to breeding materials such as stored in genebanks (if legislation is in place); registration of genetic resources and traditional knowledge; management of PIC; distribution, use and mobilization of benefit sharing funds; and negotiation of terms with third parties. Some progress is being made, but there is still a long way to go. Limited capacities at the local, community level, to apply and implement often complex regulations, remains a particular challenge.

The ability of national regulatory frameworks to support new roles and responsibilities varies greatly as the cases indicate. For example, although Jordan has adopted a comprehensive framework of agricultural policies and laws, ABS issues, especially in relation to PPB, have not yet been dealt with in a clear, concise and operational manner. The ABS team has made a start by identifying key issues in relation to the various elements of $\mathrm{PPB}$, but the general lack of knowledge among researchers, policymakers and farmers has been a challenge. In Honduras, despite more than a decade of efforts by case study partners, it has not been possible to make any policy or legal changes in support of PPB. The Honduras case is an example of how difficult it sometimes is to change ingrained institutional (research) practices.

An important point arising from the cases is the role of farmer and indigenous community organizations. The Nepal case makes the strongest argument for this role by saying that the 
establishment of a representative institution of farmers with a mandate for the conservation and sustainable use of genetic resources and traditional knowledge is a prerequisite for protecting the rights of a community during implementation of any ABS regime. In Nepal, methods employed to strengthen farmers' organizational capacities included village-level workshops, folk song competitions, biodiversity fairs, rural street dramas and farmers' training in ABS and their right to contribute to this process of local organization. Honduras, Cuba and China are other examples where dynamic farmer organization processes are occurring.

\subsection{Rights}

Ownership and, more so, intellectual property rights based on formal law are often detached from a sociocultural context where sharing and freely exchanging resources (seeds) and traditional knowledge is the norm. In the case of PPB in China and Jordan, in particular, ownership and rights questions have arisen. In Jordan, among the PPB farmers, some do not attribute individual ownership to the new varieties while others do. In China, farmers, as custodians of the nation's plant genetic resources, have raised their voice to be rewarded not only for their contributions to crop improvement, but also for their conservation efforts. How to deal with these emerging issues will define the effective beneficiaries and the future incentives for PPB. Privatizing a traditional common good (a seed or variety) will affect perceptions and could possibly curtail future innovation at the local level and harm partnerships with research institutions.

Sharing knowledge and expertise is a concrete and important way to share benefits. As the Syria case argues, combining farmers' knowledge with that of professional breeders enables farmers to benefit from their contributions to the global genetic pool, for example, through added value to their crops, improved livelihoods and increased income. In Honduras, throughout the participatory breeding process, farmers received extensive agronomic support from the NGO facilitating the farmer research process. None of the farmers had segregated material before and had to learn how to select for characteristics that might vary from one generation to the next. This was also a new process for the NGO and a good deal of mutual learning took place.

The concept of farmers' rights, as promoted by the ITPGRFA, has made inroads in some countries (most notably in Nepal and, to some extent, Peru and Jordan), but it remains a challenge to integrate and operationalize the three basic rights referred to in the treaty in national policy and laws: protection of traditional knowledge relevant to PGRFA; equitable sharing of benefits arising from the use of PGRFA; and participation in decisions, at the national level, on matters related to the conservation and sustainable use of PGRFA [29]. In some countries, even acceptance of the concept is not that easy, given the political context (e.g., Honduras, Syria, Cuba and China). However, the case studies have explored a variety of ways to put the concept into practice (Table 1).

In Honduras, Nepal and Peru, the risk of biopiracy seems to be a serious concern for smallholder farmers. Specific traits in the landraces that farmers have conserved or improved through PPB might become materials protected under UPOV-91 or one or more national patent regimes. In Honduras, the country case study team fears that, given the total neglect by the government of informal seed systems, local varieties and participatory crop improvement, should a law for the protection of plant varieties 
eventually pass, smallholder farmers are unlikely to enjoy much protection from farmers' rights regulations.

Table 1. Overview of farmers' rights in practice.

\begin{tabular}{ll}
\hline Right & Practice \\
\hline Protection of traditional & De facto and formal legal recognition of collective forms of traditional knowledge \\
knowledge relevant to & and practices; \\
PGRFA & Use of prior informed consent for research and development initiatives; \\
& Legal recognition of community biodiversity registers; \\
& De facto acceptance and formal legal recognition of farmers as competent plant \\
& breeders and conservationists of biodiversity; \\
& De facto and legal acceptance of farmers as bona fide seed producers; \\
& De facto and legal acceptance of local forms of farmer and community organization \\
& (including agro-biodiversity zones). \\
\hline Participation in benefit & Capacity building among farmers and community members in a variety of areas \\
sharing & related to crop improvement, conservation of biodiversity and rural livelihood \\
& improvement; \\
& Involving women through special activities in crop improvement and other rural \\
& livelihood improvement efforts; \\
& Improved (local) varieties; access to new breeding materials and related knowledge \\
& and technologies in hands of the formal sector; \\
& Increased crop diversity; access to new resources for conserving biodiversity in situ; \\
& Improved local seed systems; establishment of local seed banks; access to new \\
& channels for the out- and inflow of seeds and related knowledge; \\
& New seed production and commercialization opportunities; \\
& Royalties arising from crop improvement; \\
& Access to local biodiversity fund. \\
\hline Participation by women and men farmers in local, regional, national and international \\
policy meetings, workshops, seminars, conferences; \\
Indirect involvement through research and development organizations. \\
\hline Participation in national \\
decision making
\end{tabular}

\subsection{Mechanisms and Incentives for $A B S$}

Given the limited implementation of ABS policy and legal frameworks worldwide, there has been little opportunity to test monitoring mechanisms intended to ensure that benefit sharing takes place. Some ideas have been proposed, from tracking flows of resources to demanding strong reporting requirements along the research and development chain [30]. PPB is an effective way to generate and share benefits. Yield increases brought about by PPB are a concrete way to improve livelihoods. The Syria case shows that no matter how many varieties are released from the formal system and no matter how much greater their yields are, farmers in marginal environments will not adopt them unless they have participated in the selection process. Analysis of the farm-level benefits and costs of barley production showed that the participation of farmers in the breeding program does not mean higher production costs. Farmers who adopt varieties bred through PPB often pay higher input costs, but gain higher net returns. As the Syria case study team argues, in addition to economic benefits, participating farmers gain in terms of increased knowledge of barley production and variety selection and from their 
collaboration with scientists and other farmers. This type of non-monetary benefit is crucial and demonstrates the overall importance of PPB and farmer participation.

Although Jordan benefits from a national law on farmers' rights, it has not yet been feasible to define clear ABS principles among PPB farmers, in particular concerning seed multiplication and distribution. Farmers do have an interpretation of benefit sharing. Some of them produced seeds and distributed some free to other farmer participants in the PPB research. One farmer sold his new variety and recorded the names of farmers who bought seeds to be able to track the diffusion process. However, how to translate this reality into adequate policy and legislation remains a challenge. In Nepal, China and Honduras, draft legislation accepts farmers as breeders of new varieties, but there is still no mechanism for providing incentives to farmer breeders.

How real or hypothetical benefits from PPB should be shared is not easy to determine. In Honduras, based on farmers' allocation of the hypothetical benefits from PPB, it is clear that they are not prepared to accord the breeder a significant portion of the benefits, even when they are using breeder materials. Instead, farmers regard their labor and skills as the main ingredients of PPB; human resources appear to be more important to them than rights over local germplasm. Thus, the longer and more complex the process of PPB, the more farmers are likely to feel they have rights over the benefits ensuing from it, regardless of where the germplasm originated. From the breeders' perspective, however, farmer selection and breeding involving breeder materials is more likely to be viewed as validation of their skills than as farmer creativity. This is particularly true if breeders have little opportunity to witness the skills and effort that farmers put into the breeding process. Just as farmers remain unaware of the resources (both human and financial) invested in plant breeding, breeders who rarely stray from the experimental station are likely to be similarly uninformed. This contrasts with the China case, where an agreement has been reached based on acceptance of joint efforts in terms of process and outcomes to share benefits through a collective mechanism (community fund) in support of community efforts.

Biodiversity or seed fairs (Cuba, Nepal and China) are important venues for the exchange of knowledge, experience and seeds. In Cuba, they were used to start a process of seed diffusion and large-scale, on-farm testing of new lines and varieties. They are a much appreciated way for the formal sector to benefit farmers, who have embraced the fairs with open arms. What is more, farmers are replicating fairs at the local level, organizing and financing them largely on their own. In China and Nepal, fairs, above, all function as exchange platforms. Seed production has good potential for generating monetary benefits. However, producing seed according to national rules and regulations is not always easy for smallholder farmers. Seed production has encountered technical, managerial and regulatory obstacles, as the cases of Jordan, China and Honduras illustrate.

Value can be added in some cases by applying a "geographic indication" designation to certain crops to distinguish specific local high-quality seeds and derived products, such as the wax maize grown in some parts of Guangxi. All the farmers within the area may join and benefit from collective production, and the certification can be applied and managed by a local farmer organization or a producer group with support from its administrative village. The Nepalese case study team is also exploring such an arrangement. A community-based biodiversity management (CBM) fund is a way to share benefits acquired from common resources in villages. In Nepal, every household in a village development committee is eligible for a loan from the fund. Experience has shown that a CBM fund 
can contribute greatly to sustainable biodiversity management in a community. After seeing how benefits can be distributed successfully through CBM funds, the project team is now investigating whether money acquired from the use of community genetic resources can go directly into the fund and be used equitably for biodiversity management and community welfare. Supporting legislation is needed, and the team is lobbying for this. The China team is experimenting with a similar mechanism.

The China team argues that not only is support needed at the local level, but a national research program on landrace conservation and improvement should also be set up as part of the working agenda of all plant breeding institutes in the country. Efforts of breeders in this area should also be recognized and evaluated in institutes' annual performance reviews. Another option is to set up a national registration system for open-pollinated varieties (OPVs), including landraces, traditional varieties and farmer-improved OPVs, in parallel with the "new varieties" protected by law. Within this system, the diversity of plant genetic resources can be captured and the contribution of breeders (both farmer breeders and formal-sector breeders) can be recognized.

Gender and other social variables also matter a great deal. In most cases, participatory fieldwork has been used to understand gender-based differences in agronomic management, crop preferences and needs (see the Syria case for a discussion). As a result, PPB activities are now organized in ways that facilitate the involvement of women farmers. This is done by coordinating the events directly with women as well as collaborating with local institutions and by creating women-only spaces. The team tries to respect local sensitivities, particularly with regard to the participation of young female farmers in public events. In China, most farmers are women, and this has led the country case study team to pay careful attention to gender issues from the start and include women in decision making. However, not all project teams have been so aware of gender differences, suggesting that more work is needed.

Effective implementation will be the ultimate test of any ABS regime. Peru, which developed a sui generis policy early on, and competent authorities (the National Institution for the Defense of Competition and Intellectual Property and the Ministry of the Environment) have made strong efforts to implement regulations. However, there is still much to do in terms of strengthening institutional capacities to apply norms and monitor their implementation.

\section{Conclusions}

Constructing ABS and traditional knowledge protection frameworks is a relatively new policy development challenge, content and process wise. Countries such as China, Nepal and Peru, have made progress with $\mathrm{ABS}$ and traditional knowledge laws and regulations, but more interaction with farmers and local communities is required to ensure that these policies and norms are informed by reality. Benefit sharing, free PIC and MAT principles are often difficult to understand and apply at local levels where more traditional and customary practices take place, based on collective identities, knowledge and practices. Novel interpretations based on field experiences are urgently needed. Local initiatives such as biocultural protocols and codes of conduct with direct input from farmers and communities can create synergies among local, national and international levels and help implementation processes. Improving communication between local-level practitioners and national and international decision-makers is another major necessity for improving ABS policy- and law-making. 
All the practices through the seven case studies, farmers and indigenous communities have become more aware of and knowledgeable about formal ABS concepts and procedures. Questions such as who owns or has property rights over seeds and breeding materials are becoming more common. Traditional practices and customary law-informed mostly by collective identities and forms of reciprocity-remain a guiding force in the case study countries and the basis for finding answers to this type of questions. Researchers and other stakeholders in the seven countries have started to acknowledge and appreciate the traditional knowledge and skills of farmers. They have become engaged in collaborative research and development efforts aimed to create synergies between formal and informal seed and innovation systems. This had led to the realization that sharing of knowledge and experience is also a form of benefit sharing that can be beneficial for farmers' livelihoods. The seven case studies have explored a remarkable variety of ways to put the concept of Farmers' Rights into practice, both overtly and less overtly, for example, through legal recognition of community biodiversity registers and de facto acceptance and formal legal recognition of farmers as competent plant breeders and conservationists of biodiversity (the right of protection of traditional knowledge relevant to PGRFA); involving women through special activities in crop improvement and other rural livelihood improvement efforts, new seed production and commercialization opportunities and access to local biodiversity fund (the right to participate in benefit sharing); and participation by women and men farmers in local, regional, national and international policy workshops, seminars, conferences (the right to participate in national decision-making).

Introduced and tested by the seven case study teams are valuable mechanisms to operationalize ABS regimes. They are examples of how key concepts and measures of the CBD and the ITPGRFA can be implemented: promotion of diverse farming systems, including the use of local crops, varieties and underutilized species; support for research that enhances biological diversity; broadening of the genetic base of crops in situ and ex situ; creation of stronger links to plant breeding and agricultural development; promotion of PPB; and a review of breeding strategies and regulations concerning variety release and seed distribution.

National governments could set up funds to permit wider adoption and adaptation of these measures allowing more farmer communities to experiment and reap the benefits. PPB efforts offer a unique example of how benefit sharing takes place in practice, with or without an overarching formal ABS or traditional knowledge policy or legal framework in place. The cases demonstrate that actors in the research and development chain participate in and generate benefits that are distributed according to a wide range of criteria that often go beyond narrowly defined policy and legal guidelines. These examples ought to be better heard and taken into consideration at national and international levels.

\section{Acknowledgments}

We acknowledge the contributions made by the ABS country case study teams from China, Cuba, Honduras, Jordan, Nepal, Peru, and Syria, on which the analysis presented in the article, is based. Country case study writers were, in alphabetical order: K. Adhikari, A. Al-Yassin, S. Ceccarelli, T. Cruz Sardiñas, A. Gallié, O. Gallardo, M. Gomez, S. Grando, S. Humphries, J. Jiménez, J. Li, Y. Mustafa, B. Paudel, H. Ríos Labrada, P. Shrestha, Y. Song, and B. Bahadur Tamang. Opinions expressed are those of the authors only. The field research was funded by the International 
Development Research Centre of Canada. We thank Arwen Bailey for her editorial support. We benefitted from the review suggestions made by three anonymous reviewers.

\section{Conflict of Interest}

The authors declare no conflict of interest.

\section{References}

1. Food and Agriculture Organization of the United Nations (FAO). 2nd State of the World's Plant. Genetic Resources for Food and Agriculture; FAO: Rome, Italy, 2010.

2. Tansey, G.; Rajotte, T. The Future Control of Food: A Guide to International Negotiations and Rules on Intellectual Property, Biodiversity and Food Security; Earthscan: London, UK; the Quaker International Affairs Program: Ottawa, Canada; International Development Research Centre: Ottawa, Canada, 2008.

3. Frison, C.; López, F.; Esquinas-Alcázar, J. Plant. Genetic Resources and Food Security: Stakeholder Perspectives on the International Treaty on Plant. Genetic Resources for Food and Agriculture; Earthscan: London, UK, 2011.

4. Halewood, M.; Lopez-Noriega, I.; Louafi, S. Crop. Genetic Resources as a Global Commons: Challenges in International Law and Governance; Earthscan: Abingdon, UK, 2013.

5. Vernooy, R.; Ruiz, M. Conclusions: Race to the Bottom versus Slow Walk to the Top. In The Custodians of Biodiversity: Sharing Access to and Benefits of Genetic Resources; Ruiz, M., Vernooy, R., Eds.; Earthscan: Abingdon, UK; International Development Research Centre: Ottawa, Canada, 2012; pp. 163-180.

6. Santilli, J. Local Varieties, Informal Seed Systems and the Seed Law: Reflections from Brazil. In Community Biodiversity Management: Promoting Resilience and the Conservation of Plant Genetic Resources; de Boef, W.S., Subedi, A., Peroni, N., Thijssen, M., O’Keeffe, E., Eds.; Routledge: Abingdon, UK, 2013; pp. 338-344.

7. Ruiz, M.; Vernooy, R. The Custodians of Biodiversity: Sharing Access to and Benefits of Genetic Resource; Earthscan: Abingdon, UK; International Development Research Centre: Ottawa, Canada, 2012.

8. Bragdon, S.; Jarvis, D.I.; Gaucham, D.; Mar, I.; Hue, N.N.; Balma, D.; Collado, I.; Latournerie, L.; Sthapit, B.R.; Sadiki, M.; et al. The agricultural biodiversity policy development process: Exploring means of policy development to support the on-farm management of crop diversity. Int. J. Biodivers. Sci. Manag. 2009, 5, 10-20.

9. Kamau, E.C.; Winter, G. Genetic Resources, Traditional Knowledge and the Law: Solutions for Access and Benefit Sharing; Earthscan: London, UK, 2009.

10. Richerzhagen, C. Protecting Biological Diversity: Effectiveness of Access and Benefit Sharing Regime; Routledge: London, UK, 2010.

11. Song, Y.; Vernooy, R. Seeds and Synergies: Innovating Rural Development in China; Practical Action Publishing: Rugby, UK; International Development Research Centre: Ottawa, Canada, 2010.

12. The Crucible Group. People, Plants and Patents; International Development Research Centre: Ottawa, Canada, 1994. 
13. Posey, D.A.; Dutfield, G. Beyond Intellectual Property: Toward Traditional Resource Rights for Indigenous Peoples and Local Communities; International Development Research Centre: Ottawa, Canada, 1996.

14. Lesser, W. Sustainable Use of Genetic Resources under the CBD: Exploring Access and Benefit-Sharing Issues; Commonwealth Agricultural Bureaux International: Wallingford, UK, 1998.

15. Bass, S.P.; Ruiz Muller, M. Protecting Biodiversity: National Laws Regulating Access to Genetic Resources in the Americas; International Development Research Centre: Ottawa, Canada, 1999.

16. The Crucible II Group. Seeding Solutions. Volume 2. Options for National Laws Governing Control over Genetic Resources and Biological Innovations; International Development Research Centre: Ottawa, Canada; International Plant Genetic Resources Institute: Rome, Italy; Dag Hammarskjold Foundation: Uppsala, Sweden, 2000.

17. The Crucible II Group. Seeding Solutions. Volume 1. Policy Options for Genetic Resources: People, Plants, and Patents Revisited; International Development Research Centre: Ottawa, Canada; International Plant Genetic Resources Institute: Rome, Italy; Dag Hammarskjold Foundation: Uppsala, Sweden, 2001.

18. Ten Kate, K.; Laird, S.A. The Commercial Use of Biodiversity: Access to Genetic Resources and Benefit Sharing; Earthscan: London, UK, 2002.

19. Carrisoza, S.; Brush, S.B.; Wright, B.D.; McGuirre, P.E. Accessing Biodiversity and Sharing the Benefits: Lessons from Implementation of the CBD; International Union for the Conservation of Nature: Gland, Switzerland, 2004.

20. Vernooy, R. Seeds that Give: Participatory Plant. Breeding; International Development Research Centre: Ottawa, Canada, 2003.

21. Vernooy, R.; Shrestha, P.; Cecarrelli, S.; Rios, H.; Song, Y.; Humphries, S. Towards New Roles, Responsibilities and Rules: The Case of Participatory Plant Breeding. In Plant Breeding and Farmer Participation; Cecarrelli, S., Guimaraes, E., Weltzien-Rattunde, E., Eds.; Food and Agriculture Organization of the United Nations: Rome, Italy, 2009; pp. 613-628.

22. Ferro, P.; Ruiz, M. Cómo Prevenir la Biopiratería en el Perú? Reflexiones y Propuestas [in Spanish]; Sociedad Peruana de Derecho Ambiental: Lima, Peru, 2005.

23. Ceccarrelli, S.; Grando, S.; Bailey, E.; Amri, A.; El-Felah, M.; Nassif, F.; Rezgui, S.; Yahyaoui, A. Farmer participation in barley breeding in Syria, Morocco and Tunisia. Euphytica 2001, 122, 521-536.

24. Ceccarrelli, S.; Grando, S. Decentralized-participatory plant breeding: An example of demand driven research. Euphytica 2007, 155, 349-360.

25. Humphries, S.; Jiménez, J.; Sierra, F.; Gallardo, O. Sharing in Innovation: Reflections on a Partnership to Improve Livelihoods and Resource Conservation in the Honduran Hillsides. In Participatory Research Conservation and Rural Livelihoods: Doing Science Together; Fortmann, L., Ed.; Wiley-Blackwell: Chichester, UK, 2008; pp. 36-54.

26. Ríos Labrada, H. Participatory Seed Diffusion: Experiences from the Field. In Plant Breeding and Farmer Participation; Ceccarrelli, S., Guimaraes, E., Weltzien, E., Eds.; Food and Agriculture Organization of the United Nations: Rome, Italy, 2009; pp. 589-612. 
27. Subedi, A.; Shrestha, P.; Upadhyay, M.; Sthapit, B.R. The Evolution of Community Biodiversity Management as a Methodology for Implementing in Situ Conservation of Agrobiodiversity in Nepal. In Community Biodiversity Management: Promoting Resilience and the Conservation of Plant Genetic Resources; de Boef, W.S., Subedi, A., Peroni, N., Thijssen, M., O’Keeffe, E., Eds.; Routledge: Abingdon, UK, 2013; pp. 11-18.

28. Sthapit, B.R.; Khadka, K.; Shrestha, P.; Subedi, S.; Prasad Poudel, I. Grassroots Breeding of Local Crops and Varieties in Support of Community Biodiversity Management and Resilience in Nepal. In Community Biodiversity Management: Promoting Resilience and the Conservation of Plant Genetic Resources; de Boef, W.S., Subedi, A., Peroni, N., Thijssen, M., O’Keeffe, E., Eds.; Routledge: Abingdon, UK, 2013; pp. 233-239.

29. Vernooy, R. Recognizing and Promoting Farmers' Knowledge and Rights: The Policy Challenges. CGIAR Consortium News 2012. Available online: http://www.cgiar.org/consortiumnews/recognizing-and-promoting-farmers-knowledge-and-rights-the-policy-challenges/ (accessed on 7 June 2013).

30. Ruiz, M.; Lapeña, I. A Moving Target: Genetic Resources and Options for Tracking and Monitoring Their International Flows; IUCN Environmental Policy and Law Paper; IUCN: Gland, Switzerland, 2007.

(C) 2013 by the authors; licensee MDPI, Basel, Switzerland. This article is an open access article distributed under the terms and conditions of the Creative Commons Attribution license (http://creativecommons.org/licenses/by/3.0/). 